The variations in uterine activity in each category are shown in Fig. 7, but, since the numbers in each group are so small, these differences are of doubtful significance.

\section{Discussion}

There are some weaknesses in the design of this study which need to be taken into account before any conclusions can be drawn from the findings. In the first place it might have been better not to rupture the membranes at all. Rupturing membranes and draining the liquor is a stimulus to the onset of labour, and in fact all our patients went into labour and delivered after six hours. The study therefore tests only whether intra-amniotic oestriol sulphate modifies uterine contractions once these have been stimulated by rupture of the membranes. To see whether oestriol in high concentration, when conveyed to the myometrium by the route which normally applies in pregnancy and in the same form as that in which it exists in vivo, has any effect on the onset of labour it would be necessary to give it by transabdominal injection before labour starts. In our view the positive findings in the present study justify such a procedure.

The control group and the test group were not the same with regard to spontaneous myometrial activity before induction and to the state of the cervix. This made it difficult to detect the effect of oestriol sulphate on myometrial activity and may have obscured a possible effect on the induction-delivery interval. These disadvantages could have been reduced had a larger number of subjects or stricter selection criteria been used. It proved difficult, however, to obtain even the present modest number of patients who satisfied all the criteria.

Attempts to define the role of oestrogens in relation to the onset of labour are not new. Pinto et al. (1967) claimed that an intravenous injection of oestradiol- $17 \beta$ stimulates labour in women at term. Our attention was first directed to a possible specific role of oestriol by the finding of Klopper and Billiewicz (1963) that women with a higher urinary oestriol excretion tended to go into labour before those with a lower output. Klopper and Dennis (1962), however, failed to find any effect from oestriol or stilboestrol given by mouth on the induction-delivery interval or on the length of labour following artificial rupture of the membranes. Thus in the light of subsequent findings the absence of any demonstrable effect following oestriol by mouth was probably due to two reasons. Firstly, oral administration of the free compound results in its prompt conjugation and excretion so that its concentration and duration of action at the myometrium are small. Secondly, though oestriol may increase myometrial activity, the results of this on the clinical features of labour may be obscured by other factors such as the state of the cervix and the cephalo-pelvic relationship. The virtue of the present study is that the actual compound made by the foeto-placental unit reaches the myometrium by the natural route. There is clear evidence that oestriol sulphate is hydrolysed by the placenta and membranes (Goebelsmann et al., 1966). Presumably the free steroid is transmitted to the maternal blood, and has its effect, if any, on the myometrium during its initial passage through the uterus and before being inactivated by reconjugation into glucosiduronate in the liver.

This is the first time that the oestriol derivative, which is present in much the largest concentration within the uterus, has been given by this route to normal women at the point of onset of labour. It is noteworthy that it should have affected uterine activity. This study, however, does not show that changes in oestriol concentration at the myometrial level play a dominant, or indeed any, part in the onset of labour.

We are indebted to our colleagues in the Aberdeen Maternity Hospital for allowing us access to their patients. The oestriol sulphate used was synthesized for us by Messrs. Organon Laboratories Ltd. and supplied by Dr. W. Tindall. We are grateful to Mr. W. Bytheway for statistical advice.

\section{REFERENCES}

Caldeyro-Barcia, R., and Sereno, J. (1961). In Oxytocin, edited by R. Caldeyro-Barcia and $\mathrm{H}$. Heller. Oxford, Pergamon Press.

Caldeyro-Barcia, R., et al. (1957). Fournal of Pharmacology and Experimental Therapeutics, 121,18

Diczfalusy, E., Cassmer, O., Alonso, C., and de Miquel, M. (1961). Recent Progress in Hormone Research, 17, 147.

Goebelsmann, U., Wiqvist, N., Diczfalusy, E., Levitz, M., Condon, G. P., and Dancis, J. (1966). Acta Endocrinologica, 52, 550.

Klopper, A., and Billewicz, W. (1963). Fournal of Obstetrics and Gynaecology of the British Commonwealth, 70,1024

Klopper, A. I., and Dennis, K. J. (1962). British Medical fournal, 2 1157 .

Klopper, A. I., Dennis, K. J., and Farr, V. (1968). British Medical fournal, 2, 158 .

Pinto, R. M., Leon, C., Mazzooco, N., and Scasserra, V. (1967). American fournal of Obstetrics and Gynaecology, 98, 540.

\title{
Radioimmunoassay of Parathyroid Hormone in Primary Hyperpara- thyroidism : Studies after Removal of Parathyroid Adenoma
}

\author{
RICHARD M. BUCKLE,* M.A., M.D., M.R.C.P.
}

\begin{abstract}
Summary : Parathyroid hormone has been measured by radioimmunoassay in eight patients with hyperparathyroidism due to parathyroid adenoma. Secretion of hormone by the adenomatas was demonstrated direct by estimating the arteriovenous gradient of parathyroid hormone across the tumours. Serial estimations following surgical removal of the adenoma showed a rapid fall in the concentration of circulating parathyroid hormone. The calculated half-life of endogenously secreted parathyroid hormone in man varied from 11.4 to $28.8 \mathrm{~min}$., with a mean of $19.8 \mathrm{~min}$.
\end{abstract}

\section{Introduction}

The radioimmunoassay of parathyroid hormone (Berson, Yalow, Aurbach, and Potts, 1963) has increased the sensitivity of its measurement, and its application in man has shown raised levels of hormone in the blood in patients with primary and secondary hyperparathyroidism (Berson and Yalow, 1966, 1968 ; Buckle, 1968a ; Melick and Martin, 1968 ; Potts, Deftos, Buckle, Sherwood, and Aurbach, 1968b.

\footnotetext{
* Consultant Physician, Department of Endocrinology, the General Hos-
} pital, Southampton, $\mathrm{SO} 94 \mathrm{XY}$. 
TABle I.-Clinical Details of the Patients with Primary Hyperparathyroidism Due to Parathyroid Adenoma

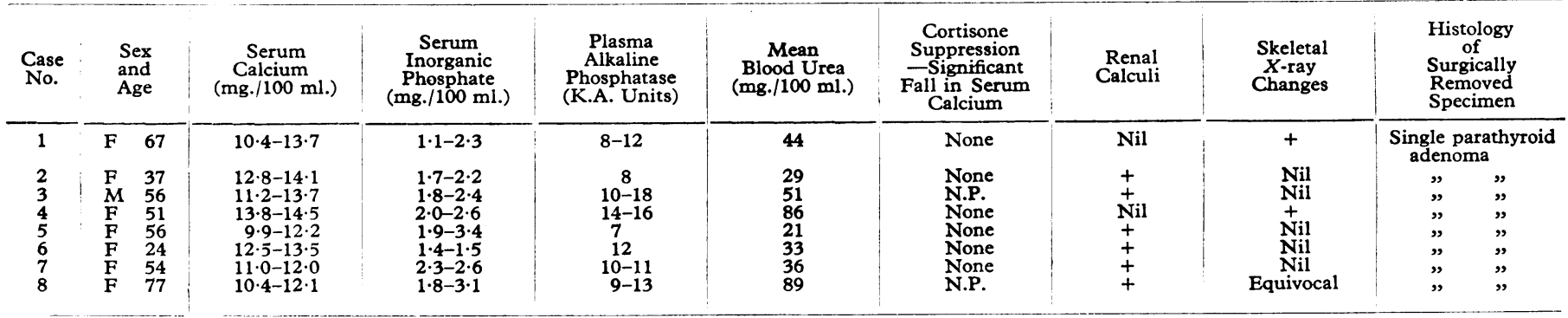

N.P. $=$ Not performed

In the present study parathyroid hormone has been measured in the blood in eight patients with primary hyperparathyroidism due to parathyroid adenoma at operation and immediately after surgical removal of the adenoma. An estimate has thereby been attained of the half-life of endogenously secreted parathyroid hormone in man.

\section{Materials and Methods}

Eight patients with histologically confirmed parathyroid adenomata were studied, and their clinical features are shown in Table I.

Collection of Samples.-At operation all four parathyroid glands were identified and the adenoma was carefully mobilized. Peripheral venous blood was collected immediately before removal of the adenoma and thereafter at timed intervals for one and a half to three hours after removal. Removal of the adenoma was confirmed by immediate examination of a frozen section and further confirmed by histological examination of the fixed tissue. In four patients venous blood draining the tumour was collected immediately before its removal, and in two of them arterial blood was also collected at the same time. The removed adenomata were rapidly deep-frozen for subsequent extraction of parathyroid hormone (Potts, Aurbach, and Sherwood, 1966).

Radioimmunoassay.-Standardization in the assay was performed against highly purified bovine parathyroid hormone (a gift of Dr. J. T. Potts and Dr. G. D. Aurbach, of the National Institutes of Health, Bethesda). Antibody to bovine parathyroid hormone was prepared by immunizing guinea-pigs. Parathyroid hormone was iodinated with ${ }^{131}$ I (Isoserve) or ${ }^{125}$ I (Union Carbide) to a specific activity of $300-400 \mu \mathrm{Ci} / \mu \mathrm{g}$. by a modification of the method of Greenwood, Hunter, and Glover (1963). Non-equilibrium assay was performed (Samols and Bilkus, 1964) and phase separation of free from antibody-bound hormone was carried out by adsorption on to dextran-coated charcoal (Herbert, Lau, Gottlieb, and Bleicher, 1965), precautions being taken to ensure adequate recognition of incubation "damage" (Buckle, 1968b ; Buckle, Chase, Aurbach, and Potts, 1969). All samples were estimated in replicate at varying concentrations in two or more separate assays.

\section{Results}

In Fig. 1 are compared the progressive reductions in bound: free ratios $(B / F)$ of labelled hormone in the presence of increasing quantities of bovine parathyroid hormone and plasma from a patient with hyperparathyroidism. The two curves are similar but not identical in shape. However, the cross-reactivity between bovine and human hormone is sufficient to allow human parathyroid hormone to be measured by the current radioimmunoassay. Parathyroid hormone in these studies is expressed in terms of its equivalence of the bovine parathyroid standard.
In each patient there was a progressive fall in the concentration of immunologically reactive parathyroid hormone in the peripheral blood during the one to two hours following removal of the adenoma. In three patients it could no longer be detected, its concentration being $<0.1 \mathrm{~m} u \mathrm{~g}$. $/ \mathrm{ml}$., the lower limit of sensitivity of the assay for unextracted plasma. In the other five it fell to values of $0 \cdot 1-0.2 \mathrm{~m} \mu \mathrm{g} . / \mathrm{ml}$. (concentration of parathyroid hormone in normal subjects $<0 \cdot 1-0.25 \mathrm{~m} \mu \mathrm{g} . / \mathrm{ml}$.).

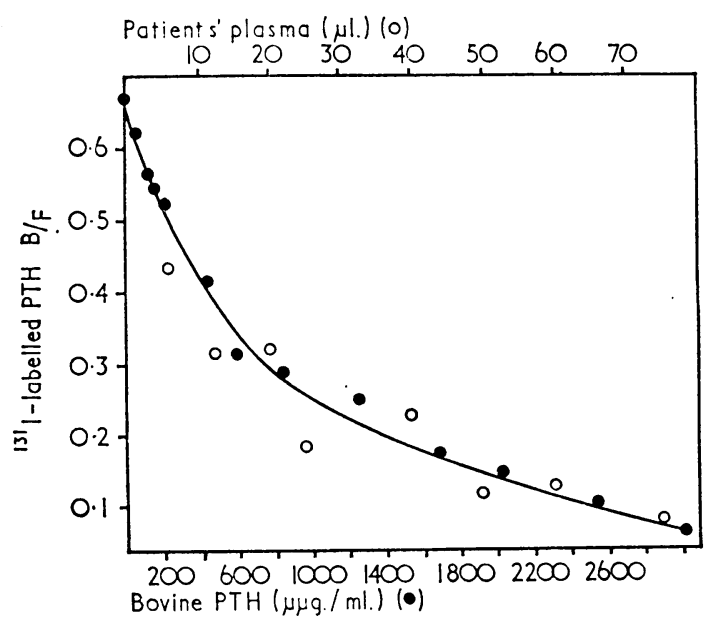

FIG. 1.-Comparison of the effects of purified bovine parathyroid hormone (O) with those of increasing quantities of plasma from a patient with a parathyroid adenoma (O) in dioplacing ${ }^{181}$ I-labelled parathyroid hormone from (O) in dioplacing Iabelled parathrom labelled parathyroid hormone to antibody is expressed as the ratio $(B / F)$ of hormone bound to antibody (B) to that unbound or free $(F)$. All values shown are means of replicate estimations. Purified bovine parathyroid hormone is expressed in $\mu \mu \mathrm{g} . / \mathrm{ml}$. final concentration of the incubate. The quantity of plasma added to the incubate in each case is shown in $\mu \mathrm{l}$.

In Table II are shown estimations of parathyroid hormone in four patients on simultaneous samples of peripheral venous blood and venous blood draining the adenoma collected imme-

TABIB II.-Comparisons of the Concentration of Parathyroid Hormone in Samples of Arterial Blood, Efluent Venous Blood Draining the Aderoma, and Peripheral Venous Blood. The Samples were Taken Simultaneously Immediately Before Removal of the Adenoma

\begin{tabular}{|c|c|c|c|c|}
\hline \multirow[b]{2}{*}{$\begin{array}{l}\text { Case } \\
\text { No. }\end{array}$} & \multicolumn{4}{|c|}{ Mean Concentration of Parathyroid Hormone $(\mathrm{m} \mu \mathrm{g} . / \mathrm{ml}$ ) } \\
\hline & $\begin{array}{l}\text { Effluent Blood } \\
\text { Draining the } \\
\text { Adenoma }\end{array}$ & $\begin{array}{l}\text { Peripheral } \\
\text { Venous } \\
\text { Blood }\end{array}$ & Arterial Blood & $\begin{array}{l}\text { Arteriovenous } \\
\text { Gradient Across } \\
\text { Adenoma }\end{array}$ \\
\hline $\begin{array}{l}1 \\
2 \\
3 \\
4\end{array}$ & $\begin{array}{l}25 \cdot 81 \\
37 \cdot 94 \\
19 \cdot 84 \\
33.79\end{array}$ & $\begin{array}{l}1.72 \\
2.05 \\
1.67 \\
2.53\end{array}$ & $\begin{array}{r}1.70 \\
1.81 \\
=\end{array}$ & $\begin{array}{l}24 \cdot 11 \\
36 \cdot 13 \\
18 \cdot 17^{*} \\
31 \cdot 26^{*}\end{array}$ \\
\hline
\end{tabular}

- Arteriovenous gradients of parathyroid hormone estimated on the assumption that only a small difference was likely between the concentrations of tion that only a small arterial biood and peripheral venous blood (see Cases 1 and 2). 
diately before its removal ; while in two patients the concentrations of hormone in arterial blood taken at the same time are also shown. The concentration of hormone in the glandular effluent blood was much greater than in the peripheral venous blood, whereas the arterial concentration was similar to that in the peripheral venous blood. Arteriovenous gradients of para-

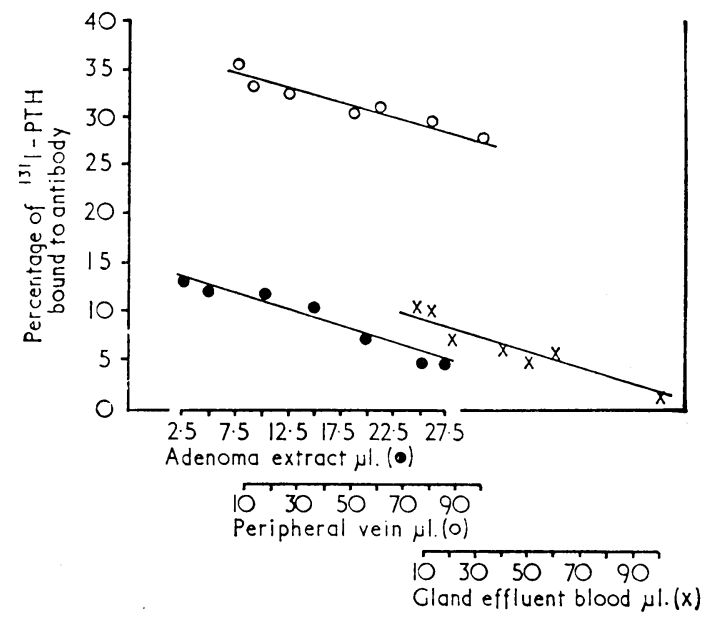

FIG. 2.-Comparison of the effects of increasing quantties of parathyroid hormone extracted from an adenoma (O) with those of increasing quantities of effluent blood from the adenoma $(x)$ and peripheral venous blood $(O)$ in displacing 131I-labelled bovine parathyroid hormone from combination with antibody. The degree of combination of 131 I latled antion. bination of body is expressed as a percentage of the total labelled hormone available for binding. The slopes of the lines are closely parallel, suggesting immunological identity. The quantities of adenoma extract, glandular effluent, and peripheral venous plasma are shown in $\mu \mathrm{l}$. thyroid hormone of $18 \cdot 17-36 \cdot 13 \mathrm{~m} \mu \mathrm{g} . / \mathrm{ml}$. plasma were thus demonstrable across the adenomata, suggesting a release of hormone from the adenomata.

In Fig. 2 are shown the effects on the binding of labelled parathyroid hormone to antibody (expressed as the percentage bound) of increasing quantities of effluent blood from an adenoma, peripheral venous blood, and increasing aliquots of an extract of the removed adenoma. The close parallelism of the three slopes suggest immunological identity between parathyroid hormone extracted from the adenoma and the circulating material measured in the blood.

The concentrations of parathyroid hormone in sequential peripheral venous blood samples following removal of the adenoma are shown for each patient in Fig. 3. In the patients in whom residual parathyroid hormone was demonstrable in the peripheral blood two or more hours after surgery it has been assumed that it is arising from the secretion of the remaining parathyroid glands, and this residual value has been subtracted from the measured concentrations, the resulting values being plotted on a logarithmic scale. In the other patients the residual value has been taken as $0.1 \mathrm{~m} \mu \mathrm{g} . / \mathrm{ml}$. (the lower limit of sensitivity of the assay). The semilogarithmic plot shows a linear decrease in the concentration of parathyroid hormone, suggesting an exponential fall in the concentration of parathyroid hormone after surgical removal of the adenoma. Estimation of the half-times of parathyroid hormone from these plots showed values of $23 \cdot 3,22 \cdot 5,22 \cdot 8,28 \cdot 8,12 \cdot 3,23 \cdot 6,11 \cdot 4$, and $14.1 \mathrm{~min}$. respectively, with a mean of $19.8 \mathrm{~min}$. In Fig. 4 are summarized the results from all eight patients. In each case the residual value has been subtracted from the measured value, and for comparison the postoperative concentration of hormone expressed as a percentage of that at the time of removal of the adenoma. The similarity of the rates of decay can be seen.
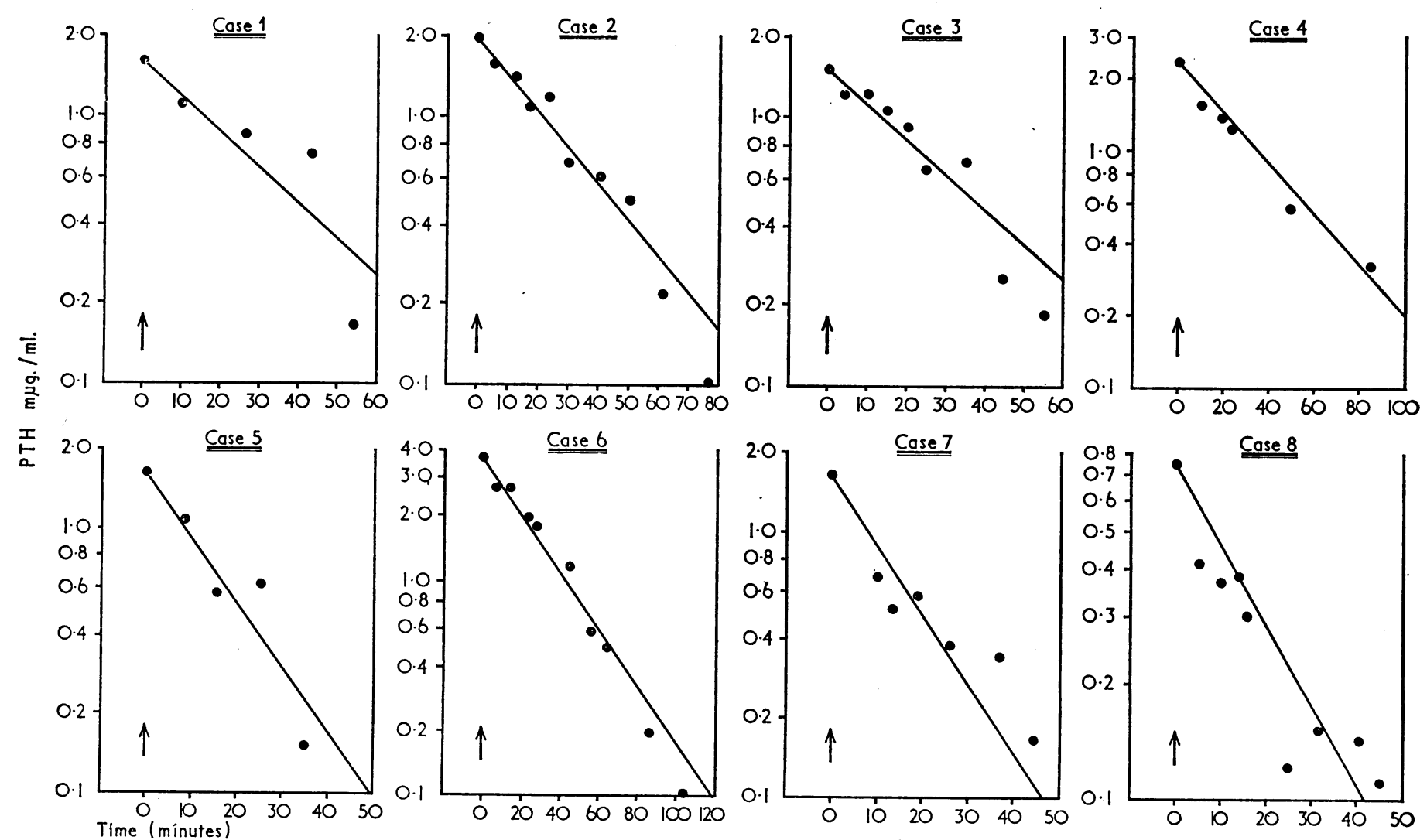

FIG. 3.-Sequential estimations of the concentrations of circulating parathyroid hormone in each patient following surgical removal of the adenoma. The arrow indicates the time of removal of the adenoma in each case. The concentration of parathyroid hormone is plotted on logarithmic scale, time on a linear scale. Each point represents the measured concentration of parathyroid hormone minus the final residual concentration of circulating hormone (or minus $0.1 \mathrm{~m} \mu \mathrm{g} . / \mathrm{ml}$., the lower limit of sensitivity of the assay). The plasma samples were estimated in replicate at multiple dilutions in two or more assays. The mean value for each sample is shown and expressed as m $\mu$. $/$ ml. plasma. 


\section{Discussion}

In each patient removal of the parathyroid adenoma was accompanied by a rapid fall in the concentration of parathyroid hormone in the blood. Histological examination confirmed that the removed tissue was a parathyroid adenoma. Careful surgical exploration of the neck and identification of all four parathyroid glands precluded so far as was possible the presence of any other adenomata. No recurrence of hypercalcaemia has been seen during follow-up. A complete removal of all parathyroid adenomatous tissue seemed likely.

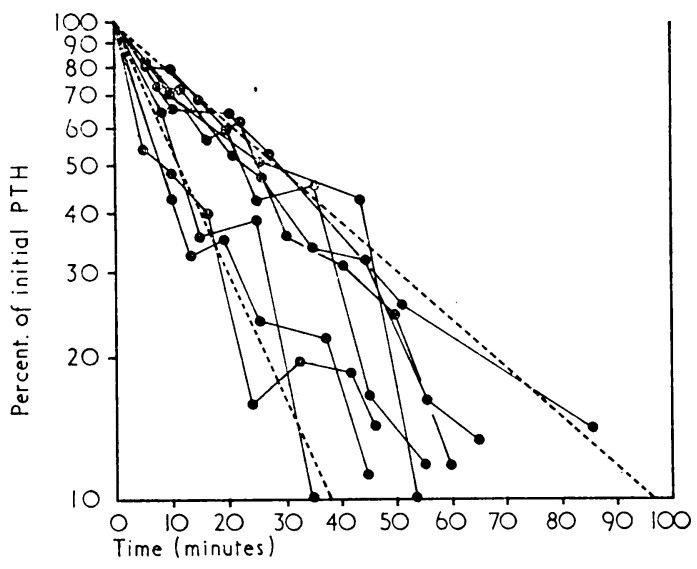

FIG. 4.-Rates of fall in the concentrations of parathyroid hormone following surgical removal of the adenomata in all eight patients. The concentration of parathyroid hormone is plotted on a logarithmic scale. In each patient the points represent the mean measured concentration of parathyroid hormone minus the residual circulating level (or minus $0.1 \mathrm{~m} \mu \mathrm{g} . / \mathrm{ml}$., the lower limit of sensitivity, in the three patients in whom none was detectable tivilly finally). For purposes of comparison between patients each corrected value is expressed as a percentage of the corrected initial immediate preoperative concentration $(100 \%)$. The dotted lines represent decay slopes for the minimum half-life of 11.4 min., and the maximum halflife of $28.8 \mathrm{~min}$., respectively.

An arteriovenous gradient of parathyroid hormone was demonstrated across the tumours, suggesting that the immunoassayable hormone measured in the peripheral blood was arising from the parathyroid adenoma. A similar demonstration of an arteriovenous gradient of parathyroid hormone has also been made across a secreting secondary parathyroid carcinomatous deposit in the lungs (Zisman et al., 1968).

The close immunological similarity between material extracted from the adenomata and that present in the glandular effluent and peripheral blood (Fig. 2) would suggest their common identity. Further, their immunological similarity (though not complete identity) with highly purified bovine parathyroid hormone suggests that parathyroid hormone was being measured in these studies.

The absence of complete immunological similarity found between human and bovine hormone confirms previous studies showing incomplete cross-reactivity between the two species (O'Riordan, Potts, and Aurbach, 1969). The lack of complete cross-reactivity almost certainly means the present method underestimates the actual quantity of human parathyroid hormone present, and the figures may need to be multiplied two to five times. The present method would, however, seem valid for comparative studies such as have been performed.

Very rapid falls in the concentration of circulating parathyroid hormone followed removal of the adenomata; the levels falling to normal, or in some cases to levels below the current sensitivity of the assay, within 45 to 140 minutes. It would seem reasonable to conclude that any residual parathyroid hormone circulating in the blood was due to a continued secretion of hormone by the remaining non-adenomatous parathyroid glands. The decrease in concentration of parathyroid hormone was exponential. Its half-life varied from 11.4 to $28.8 \mathrm{~min}$., with a mean of $19.8 \mathrm{~min}$. The survival time of circulating exogenous human or animal parathyroid hormone when administered to man is not known. The present calculated values, however, compare closely with those obtained from studies in animals. Exogenous radioiodine-labelled bovine parathyroid hormone in rats has been shown to have a half-life of $22 \mathrm{~min}$. (Melick, Aurbach, and Potts, 1965), and the unlabelled hormone in cows a half-life of $18 \mathrm{~min}$. (Sherwood, Mayer, Ramberg, Kronfeld, Aurbach, and Potts, 1968), while endogenously secreted hormone has a half-life of 10-25 min. both in normal and in adapted parturient cows (Potts et al., 1968a; Buckle, Aurbach, and Potts, 1968).

It remains uncertain whether parathyroid hormone is excreted by the kidneys. Berson and Yalow (1968) suggest that hormone or immunologically recognizable fragments of parathyroid hormone are normally excreted in the urine, though Melick et al. (1965) could find no evidence for this. In the present study estimations on the urine were not performed. None of the patients had gross impairment of renal function and no correlation could be found between the measured half-life of parathyroid hormone and the degree of any impairment of renal function.

The secretion rate of parathyroid hormone in these patients may be calculated from the circulating concentration of hormone, its volume of distribution, and its half-life ; for secretion rate should equal its rate of disappearance. The mean circulating concentration of hormone before removal of the adenomata was 2.01 (range $0.92-3.79 \mathrm{mug} . / \mathrm{ml}$.) Parathyroid hormone distributes throughout the extracellular fluid space (Melick et al., 1965), while its mean half-life in these patients was $19.8 \mathrm{~min}$. Calculations would suggest a secretion rate of parathyroid hormone in these patients of 9.1-37.5 (mean 19.9) $\mathrm{m} \mu \mathrm{g}$. $/ \mathrm{kg}$. body weight-min., which amounts to a mean daily total of $1.4 \mathrm{mg}$. Such a value is considerably greater than the estimated normal rates of secretion in animals. On the basis of immunoassay Care, Sherwood, Potts, and Aurbach (1966) reported a normal rate of $2-5 \mathrm{~m} \mu \mathrm{g} . / \mathrm{kg} . / \mathrm{min}$. in goats, while on bioassay normal rates of 0.6 and $2.6-6 \mathrm{~m} \mu \mathrm{g} . / \mathrm{kg} . / \mathrm{min}$. have been found in dogs (Copp, 1960) and rats (Aurbach, 1966), assuming purified parathyroid hormone to have a potency of 2,500 to 3,000 units/mg. (Potts et al., 1966).

The concentrations of parathyroid hormone in the removed adenomata in four patients were $43-57 \mu \mathrm{g}$. $/ \mathrm{g}$. wet weight of adenoma. These values compare with a content of $56 \mu \mathrm{g} . / \mathrm{g}$. wet weight in an adenoma reported by Sherwood, O'Riordan, Aurbach, and Potts, 1967) and a concentration of $13 \mu \mathrm{g}$. $/ \mathrm{g}$. wet weight in a secreting parathyroid carcinoma (Zisman et al., 1968). The weight of the adenomata varied from 0.45 to 1.34 g., so that the total quantity of parathyroid hormone in the adenomata at the time of their removal was 19-76 $\mu \mathrm{g}$. This suggests that a complete resynthesis of parathyroid hormone was occurring every 20 to 70 minutes in order to supply the mean total daily secretion of $1.4 \mathrm{mg}$. in these patients. The requirement for such a high rate of biosynthesis of hormone may be a factor limiting the severity of the clinical manifestations in patients with adenomata.

Recent studies have shown that rapid reciprocal alterations occur in the secretion of parathyroid hormone in response to changes in the concentration of serum calcium or magnesium (Ramberg, Mayer, Kronfeld, Aurbach, Sherwood, and Potts, 1967 ; Potts et al., 1968b ; Buckle, Care, Cooper, and Gitelman, 1968); while it is now recognized that the rate of action of parathyroid hormone is rapid (Talmage, Doty, Cooper, Yates, and Neuenschwander, 1965 ; Chase and Aurbach, 1967 ; Parsons and Robinson, 1968). The short half-life of the hormone will ensure that the duration of any alterations in its concentration is short-lived. It would seem likely that the parathyroid glands normally exert a more important acute regulatory effect on calcium homoeostasis than is commonly ascribed to them. 
The recognition of raised plasma concentrations of parathyroid hormone may be of value in the diagnosis of primary hyperparathyroidism, but insufficient patients have yet been studied to establish what degree of overlap may exist with cases of hypercalcaemia due to other causes. Nevertheless, the very high concentrations of parathyroid hormone found in the glandular effluent blood in the present study suggest that retrograde catheterization of the innominate and internal jugular veins may be of value in the preoperative localization of a tumour.

I wish to thank my surgical colleagues Mr. John Vinnecombe, Mr. John Webster, and Mr. John Lloyd-Davies for their unstinted co-operation and their good-natured tolerance in allowing me to collect samples during operation, and also the physicians and pathologists in the Wessex Region for all their kind help.

I should like to thank the Wessex Regional Hospital Board for its provision of the endocrine laboratory facilities and the Fleming Memorial Foundation, the Smith Kline and French Foundation, and the Dowager Countess Eleanor Peel Trust for their generous financial assistance.

\section{REFERENCES}

Aurbach, G. D. (1966).) Cited in Potts, J. T., et al. (1968).

Berson, S. A., and Yalow, R. S. (1966). Science, 154, 907.

Berson, S. A., and Yalow, R. S. (1968). Journal of Clinical Endocrinology, 28, 1037.

Berson, S. A., Yalow, R. S., Aurbach, G. D., and Potts, J. T. (1963). Proceedings of the National Academy of Sciences, 49, 613.

Buckle, R. M. (1968a). fournal of the Royal College of Physicians of London, 3, 77.

Buckle, R. M. (1968b). In Proceedings of the International Symposium on Protein and Polypeptide Hormones. Liege. In press.

Buckle, R. M., Aurbach, G. D., and Potts, J. T. (1968). In Protein and Polypeptide Hormones, edited by M. Margoulies, p. 389. Amsterdam, Excerpta Medica Foundation.
Buckle, R. M., Care, A. D., Cooper, C. W., and Gitelman, H. J. (1968). fournal of Endocrinology, 42, 529.

Buckle, R. M., Chase, L. R., Aurbach, G. D., and Potts, J. T. (1969). fournal of Laboratory and Clinical Medicine. Submitted for publication.

Care, A. D., Sherwood, L. M., Potts, J. T., and Aurbach, G. D. (1966). Nature, 209, 55.

Chase, L. R., and Aurbach, G. D. (1967). Proceedings of the National Academy of Sciences, 58, 518.

Copp, D. H. (1960). Bone as a Tissue, edited by K. Rodahl, J. T. Nicholson, and E. M. Brown, p. 289. New York, McGraw-Hill.

Greenwood, F. C., Hunter, W. M., and Glover, J. S. (1963). Biochemical fournal, 89, 114.

Herbert, V., Lau, K. S., Gottlieb, C. W., and Bleicher, S. J. (1965). fournal of Clinical Endocrinology and Metabolism, 25, 1375.

Mclick, R. A., Aurbach, G. D., and Potts, J. T. (1965). Endocrinology, 77, 198.

Melick, R. A., and Martin, T. J. (1968). In Parathyroid Hormone and Thyrocalcitonin, edited by R. V. Talmage and L. F. Bélanger, p. 440. Amsterdam, Excerpta Medica Foundation.

O'Riordan, J. L. H., Potts, J. T., and Aurbach, G. D. (1969). Proceedings of the Fifth European Symposium on Calcified Tissues. In

Parsons, J. A., and Robinson, C. J. (1968). fournal of Physiology, 194,

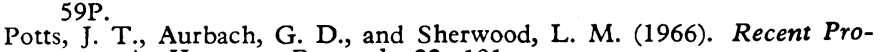
gress in Hormone Research, 22, 101

Potts, J. T., et al. (1968a). In Parathyroid Hormone and Thyrocalcitonin, edited by R. V. Talmage, and L. F. Bélanger, p. 407. Amsterdam, Excerpta Medica Foundation.

Potts, J. T., Deftos, L. J., Buckle, R. M., Sherwood, L. M., and Aurbach, G. D. (1968b). In Radioisotopes in Medicine: In Vitro Studies, edited by R. L. Hayes, F. A. Goswitz, and B. E. P. Murphy, p. 207 Tennessee, Oak Ridge Associated Universities.

Ramberg, C. F., Mayer, G. P., Kronfeld, D. S., Aurbach, G. D., Sherwood, L. M., and Potts, J. T. (1967). American fournal of Physiology, 213, 878.

Samols, E., and Bilkus, D. (1964). Proceedings of the Society for Experimental Biology and Medicine, 115, 79.

Sherwood, L. M., Mayer, G. P., Ramberg, C. F., Kronfeld, D. S., Aurbach, G. D., and Potts, J. T. (1968). Endocrinology, 83, 1043. Sherwood, L. M., O'Riordan, J. L. H., Aurbach, G. D., and Potts, J. T. (1967). Fournal of Clinical Endocrinology, 27, 140.

Talmage, R. V., Doty, S. B., Cooper, C. W., Yates, C., and Neuenschwander, J. (1965). In The Parathyroid Glands: Ultrastructure, Secretion and Function, edited by P. J. Gaillard, R. V. Talmage, Secretion and Function, edited by P. University of Chicago Press. Zisman, E., et al. (1968). American łournal of Medicine, 45, 619.

\title{
Metabolic Studies, Aldosterone Secretion Rate, and Plasma Renin after Carbenoxolone Sodium
}

\author{
J. H. BARON,; D.M., M.R.C.P.; J. D. N. NABARRO, † M.D., F.R.C.P.; J. D. H. SLATER, † M.A., M.R.C.P. \\ R. TUFFLEY, $\ddagger$ M.B., B.S., M.R.C.P.
}

\begin{abstract}
Summary : A formal metabolic study of carbenoxolone sodium (Biogastrone) $300 \mathrm{mg}$./day has been performed for 17 days on a woman with gastric ulcer who in a previous 21-day trial, on a 52-mEq sodium diet, showed weight gain, retention, and rise in plasma sodium and chloride concentrations, as well as hypokalaemia without change in potassium balance. In the present trial sodium intake was restricted to $26 \mathrm{mEq} /$ day; while plasma electrolyte changes of lesser degree still occurred, there was no retention of water, sodium, or chloride. Aldosterone secretion in the control period was $202 \mu \mathrm{g} . / 24$ hours, and fell to $74 \mu \mathrm{g} . / 24$ hours after carbenoxolone, but plasma renin was unchanged.

These results suggest that the mineralocorticoid effects of carbenoxolone (and presumably of liquorice and its other derivatives) are due to an intrinsic aldosterone-like action, and that, with sodium deprivation, aldosterone secretion is suppressed by a mechanism which is not renin-mediated-possibly hypokalaemia.
\end{abstract}

\section{Introduction}

We have previously reported detailed studies of the metabolic changes resulting from the administration of carbenoxolone sodium (Biogastrone), $300 \mathrm{mg}$./day for 21 days, to four patients with peptic ulcer (Baron and Nabarro, 1968). Weight gain and sodium and chloride retention were observed as well as hypokalaemia without appreciable changes in potassium balance. After reviewing the clinical, metabolic, and experimental studies of liquorice and glycyrrhizinic and glycyrrhetinic acids and their salts (carbenoxolone sodium is the sodium hemisuccinate of glycyrrhetinic acid) it was suggested that the metabolic actions of these compounds were essentially identical, varying with dose and duration of administration, and resembled those of aldosterone.

* Lately Senior Medical Registrar.

† Physician.

¥ Wellcome Research Fellow, Institute of Clinical Research. Institute of Clinical Research, the Middlesex Hospital Medical School,
London W.1. 